\title{
Enhancement of Heat Transfer in Partially Heated Vertical Channel Under Mixed Convection by Using $\mathrm{Al}_{2} \mathrm{O}_{3}$ Nanoparticles
}

\author{
Hasan Celik ${ }^{\mathrm{a}}$, Moghtada Mobedi ${ }^{\mathrm{b}}$, Oronzio Mancac, and Bernardo Buonomoc

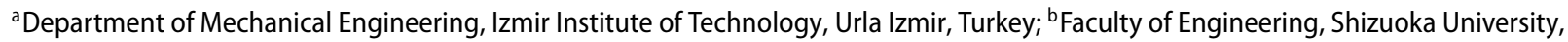 \\ Hamamatsu, Japan; 'Dipartimento di Ingegneria Industriale e dell'Informazione, Università degli Studi della Campania "Luigi Vanvitelli," \\ Aversa (CE), Italy
}

\begin{abstract}
Laminar mixed convection in a two-dimensional symmetrically and partially heated vertical channel is investigated. The heaters are located on both walls and uniform temperature is applied on the heated sections. The number of heaters is considered as 1, 4, 8 , and 10 . Aluminum oxide/water nanofluid is considered as working fluid and the inlet velocity is uniform. The continuity, momentum and energy equations with appropriate boundary conditions are solved in dimensionless form, numerically. The study is performed for Richardson number of 0.01 and 10, Reynolds number of 100 and 500, and nanofluid volume fraction of $0 \%$ and $5 \%$. Based on the obtained velocity and temperature distributions, the local and mean Nusselt number is calculated and plotted for different cases. The variation of the mean Nusselt number with the number of the heated portions is also discussed. It is found that the addition of nanoparticles into the base fluid increases mean Nusselt number but the rate of increase depends on Reynolds, Richardson numbers and number of heated portions. It is possible to increase mean Nusselt number $138 \%$ by increasing Reynolds number from 100 to 500 , Richardson number from 0.01 to 10 and number of heated portions from 1 to 10 when volume fraction value is $5 \%$.
\end{abstract}

\section{Introduction}

Conventional techniques for heat transfer enhancement are not appropriate for the modern industrial applications due to the requirement of high heat transfer rate to/from the systems. One of the recent popular methods for enhancement of heat transfer is the use of nanofluid. A nanofluid is a fluid involving high conductive nanoparticles with a diameter smaller than $100 \mathrm{~nm}$. Thermal conductivity of conventional heat transfer fluids can be increased nearly two times with the addition of a very small amount of nanoparticles [1]. The rate of heat transfer enhancement by using nanofluid depends on the concentration, size, shape, and the material of the nanoparticle. An in-depth review on the application of nanofluids is reported in [2-4]. Several industrial applications of nanofluids for enhancement of heat transfer in thermal systems such as water based heating and cooling systems, engine cooling, liquid cooling of electronic equipment, domestic refrigerator, nuclear reactors, fuel cells, cooling of manufacturing and cutting machines, cooling of transformers, and heat pipes were reported in literature [5-11].

Mixed convection heat transfer, as a mode of heat transfer, takes attention of researchers due to its presence in many practical applications such as cooling of electronic equipment, heat exchangers and building energy systems. Mixed convection occurs when the effects of forced and natural convections are comparable. When the flow rate is fixed in the inlet of the channel, flow reversals may occur inside the domain because of the buoyancy force near the hot wall. The occurrence of reversal flows makes the analysis of mixed convection problem more difficult.

Literature survey shows that several studies on the mixed convection heat transfer using nanofluids were reported [12-19]. A comprehensive review of the studies on nanofluid mixed convection heat transfer can be found in Refs. [20-22]. The problem of mixed convection in a vertical porous channel for nanofluids and pure fluids was investigated by Memari et al. [23] and they take the influences of viscous heating and inertial force into account. Van Gorder et al. [24] analyzed a twofluid vertical channel flow in mixed convection with clear fluid and nanofluid. They declared that the addition of nanofluid modified thermal properties of the fluid favorably. Amrei and Dehkordi [25] performed computational fluid dynamics simulation of mixed convection flow of

CONTACT Hasan Celik hasancelik@iyte.edu.tr Department of Mechanical Engineering, Izmir Institute of Technology, Urla Izmir 35430, Turkey. Color versions of one or more of the figures in this paper can be found online at www.tandfonline.com/uhte. 
regular and nanofluids in porous and clear vertical channels. Fully developed mixed convection in a vertical channel filled by a nanofluid studied by Grosan and Pop [26]. They considered fully developed mixed convection between parallel vertical plates with asymmetrical uniform wall temperature boundary condition both analytically and numerically. Mixed convection of nanofluids in a vertical channel partially filled with highly porous medium was investigated by Hajipour and Dehkordi [27]. The effects of Brownian motion and thermophoresis were also considered in their model. The results showed that nanofluid enhances the convective heat transfer. Xu et al. [28] evaluated the laminar fully developed mixed convection of nanofluids between two paralleled vertical flat plates. The governing equations were solved by means of the similarity and homotopy analysis method. It was found that heat transfer characteristics were improved by employing the proper nanofluids. An analysis on fully developed steady, laminar, incompressible flow in a vertical channel, filled with a copper nanofluid in a region and clear viscous fluid in the other region, was accomplished by Farooq and Zhi-Liang [29]. Results for different values of mixed convection parameters, Brownian motion parameter and thermophoresis parameter were obtained and presented. The effect of these parameters on fluid flow and heat transfer at the interface of the two regions were showed.

Mixed convection of nanofluid, water based with alumina, inside a vertical microchannel was theoretically studied by Malvandi and Ganji [30] considering the Brownian motion and thermophoresis diffusivities. The obtained results showed that the heat transfer rate was enhanced by increasing the volume fraction, the slip parameter and the mixed convection parameter but a pressure drop increase was also detected. Transient two-dimensional mixed convection of nanofluids in the entrance region of a vertical parallel-plate channel partly filled with a porous medium was numerically investigated by Hajipour et al. [31] under the constant wall temperature. Viscous dissipation, Brownian diffusion and thermophoresis effects were considered in the energy equation. Fakour et al. [32] investigated laminar fully developed mixed convection in vertical channels with nanofluids. The effects of the Grashof number, Prandtl number, and Reynolds number on the nanofluid flows were examined and the effect of Brownian motion and thermophoresis were also taken into account. The results indicated that the presence of nanoparticles enhances heat transfer. An investigation on a fully-developed mixed convection of nanofluids $\left(\mathrm{Al}_{2} \mathrm{O}_{3}\right.$-water $)$ in a vertical channel was numerically provided by Chen et al. [33]. In their analysis, the effects of the Brinkman number, Reynolds and Grashof numbers and volumetric concentration of nanoparticles were studied. An experimental and numerical investigation on mixed convection of nanofluids in vertical rectangular channels which is partially filled with open-cell metal foam was performed by Hajipour and Dehkordi [34]. The study was performed for constant heat flux at walls and $\mathrm{Al}_{2} \mathrm{O}_{3}$-water nanofluids with different concentrations. A study on pressure drop and thermal characteristics of $\mathrm{Al}_{2} \mathrm{O}_{3}$-water nanofluid flow in horizontal annuli under constant heat flux boundary conditions applied to both inner and outer walls was done by Moghari et al. [35] numerically. They analyzed the effects of nanoparticle volume fraction, heat flux ratio, radius ratio and Grashof number on heat transfer and showed that Nusselt number increases by increase of nanoparticle volume fraction, heat flux, radius ratios and Grashof number.

As can be seen from the above literature review, studies on nanofluid mixed convection heat transfer have been performed. In all of these studies, constant temperature or uniform heat flux were applied to the walls of the channels. The aim of this study is to analyze nanofluid mixed convection heat transfer in vertical channels whose walls are partially heated and, to the best of our knowledge, it was not handled before. Aluminum oxide/water nanofluid flows in the channel and heat is transferred from the heated plates with constant temperature to the nanofluid. Four different number of heated sections on walls as $1,4,8,10$ are studied. The governing equations (i.e. continuity, momentum and energy equations) are solved in dimensionless form. The effects of governing parameters which are Richardson, number of heaters and volume fraction of nanoparticles on flow and temperature fields in the channel are studied. To the best of our knowledge, the study is original and the obtained results provide useful information for designers who intend to apply nanofluid in cooling/heating of partially conductive surfaces.

\section{Considered problem}

Mixed convection in vertical channels, shown in Figure 1, is studied. The fluid flow inside the channel is considered as incompressible, laminar and steady. The thermophysical properties of fluid are assumed to be constant with exception of density in buoyancy term of the momentum equation. The nanoparticles are considered to be in thermal equilibrium with the water. Therefore, there is no slip of velocity and temperature between the nanoparticles and the base fluid.

Four channels with number of heater of $1,4,8$, and 10 are studied. The channel has the width and height of $\mathrm{w}$ and $\mathrm{H}$ respectively while its depth is too long. The aspect ratio of height to the width of channel $(\mathrm{H} / \mathrm{w})$ is 20 . The 


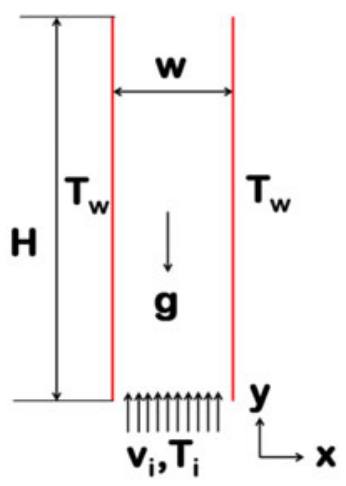

(a)

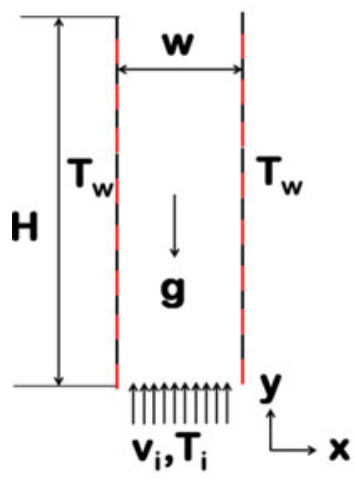

(c)

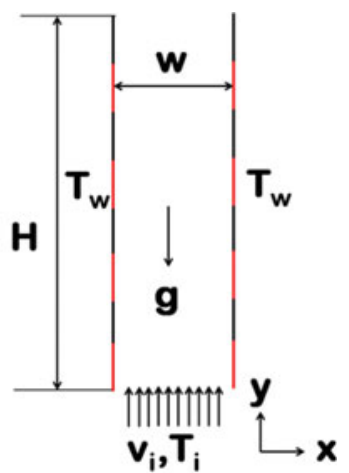

(b)

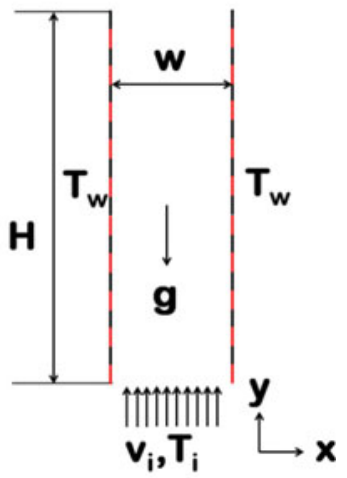

(d)
Figure 1. The considered partially heated channels, (a) fully heated, (b) 4 heated plates, (c) 8 heated plates, (d) 10 heated plates.

fluid flowing through the channel is water assisted with $\mathrm{Al}_{2} \mathrm{O}_{3}$ nanoparticles to improve its thermal conductivity. Uniform velocity and temperature profiles exist at the inlet boundary. Viscous dissipation and radiation heat transfer are neglected and gravity acts in the $y$ direction. The heated sections on the walls are maintained at constant temperature of $T_{w}$ and the nonheated sections are insulated. The gradient of velocity and temperature are taken as zero for the outlet boundary condition (i.e., no diffusion transport at the outlet boundary). The study is performed for nanoparticle concentration of $0 \%$ and $5 \%$, Richardson number of 0.01 and 10 and Reynolds number of 100 and 500 .

The temperature difference between solid nanoparticles and fluid is small and the nanoparticle concentration is low. Hence, a single-phase model approach is employed in this study. The thermophysical properties of the nanoparticles and water are considered at $25^{\circ} \mathrm{C}$. Prandtl number is taken as 6.7 for the base fluid for the entire study, however the thermophysical properties of the nanofluid is changed according to the nanoparticle concentration.

\section{The governing equations and boundary conditions}

The dimensionless continuity, momentum and energy equations under the described assumptions can be expressed as:

$$
\begin{aligned}
\frac{\partial U}{\partial X}+\frac{\partial V}{\partial Y}= & 0 \\
U \frac{\partial U}{\partial X}+V \frac{\partial U}{\partial Y}= & -\frac{\partial P}{\partial X}+\frac{1}{\operatorname{Re}} \frac{\mu_{n f}}{v_{f} \rho_{n f}}\left(\frac{\partial^{2} U}{\partial X^{2}}+\frac{\partial^{2} U}{\partial Y^{2}}\right) \\
U \frac{\partial V}{\partial X}+V \frac{\partial V}{\partial Y}= & -\frac{\partial P}{\partial Y}+\frac{1}{\operatorname{Re}} \frac{\mu_{n f}}{v_{f} \rho_{n f}}\left(\frac{\partial^{2} V}{\partial X^{2}}+\frac{\partial^{2} V}{\partial Y^{2}}\right) \\
& +\frac{(\rho \beta)_{n f}}{\rho_{n f} \beta_{f}} \operatorname{Ri\theta } \\
U \frac{\partial \theta}{\partial X}+V \frac{\partial \theta}{\partial Y}= & \frac{\alpha_{n f}}{\alpha_{f}} \frac{1}{\operatorname{Re} \operatorname{Pr}}\left(\frac{\partial^{2} \theta}{\partial X^{2}}+\frac{\partial^{2} \theta}{\partial Y^{2}}\right)
\end{aligned}
$$

where $\mathrm{U}$ and $\mathrm{V}$ the dimensionless velocity components in the $x$ and $y$ directions, respectively, $P$ is the dimensionless pressure and $\theta$ is the dimensionless temperature of the fluid. $\mu, \rho, \beta, \alpha$ and $v$ are dynamic viscosity, density, thermal expansion coefficient, thermal diffusivity and kinematic viscosity. $n f$ refers to properties of nanofluid while $f$ corresponds to pure fluid. The dimensionless parameters for the problem can be expressed as:

$$
\begin{aligned}
\operatorname{Re} & =\frac{v_{i} w}{v_{f}} ; \quad G r=\frac{g \beta_{f} \Delta T w^{3}}{v_{f}^{2}} ; \quad X=\frac{x}{w} ; \quad Y=\frac{y}{w} ; \\
U & =\frac{u}{v_{i}} ; \quad V=\frac{v}{v_{i}} ; \quad P=\frac{p w}{v_{i} \mu_{f}} ; \theta=\frac{T-T_{i}}{T_{w}-T_{i}} \\
R i & =\frac{G r}{\operatorname{Re}^{2}}
\end{aligned}
$$

The dimensional parameters for the problem are clearly shown in Figure 1. The dimensionless boundary conditions for the Eqs. (1-4) can be expressed as:

$$
\begin{array}{ll}
Y=0 & U=0, V=1, \theta=0 \\
X=0.5 & \frac{\partial U}{\partial X}=\frac{\partial V}{\partial X}=\frac{\partial \theta}{\partial X}=0 \\
X=1 & U=V=0, \theta=1 \text { (for heated portions), } \\
& \frac{\partial \theta}{\partial X}=0 \text { (for insulated parts) }
\end{array}
$$

For the outlet of channel, a special treatment is done and explained in the next section. Nanofluid thermophysical properties based on the properties of water and $\mathrm{Al}_{2} \mathrm{O}_{3}$ can be evaluated by using the following relations [36]:

$$
\begin{aligned}
\rho_{n f} & =(1-\phi) \rho_{f}+\phi \rho_{s} \\
\left(\rho c_{\mathrm{p}}\right)_{n f} & =(1-\phi)\left(\rho \mathrm{c}_{\mathrm{p}}\right)_{f}+\left(\rho \mathrm{c}_{\mathrm{p}}\right)_{s}
\end{aligned}
$$




$$
\begin{aligned}
(\rho \beta)_{n f} & =(1-\phi)(\rho \beta)_{f}+(\rho \beta)_{s} \\
\alpha_{n f} & =k_{n f} /\left(\rho c_{\mathrm{p}}\right)_{n f}
\end{aligned}
$$

where in the above equations $s$ refers to properties of the solid phase which is nanoparticles and $\phi$ represents nanoparticle concentration. The effective dynamic viscosity and thermal conductivity of the nanofluid can be evaluated as follows [36]:

$$
\begin{aligned}
& \mu_{n f}=\mu_{f}(1-\phi)^{-2.5} \\
& k_{n f}=k_{f}\left[\frac{\left(k_{s}+2 k_{f}\right)-2 \phi\left(k_{f}-k_{s}\right)}{\left(k_{s}+2 k_{f}\right)+\phi\left(k_{f}-k_{s}\right)}\right]
\end{aligned}
$$

The wall heat flux can be described in terms of dimensionless temperature gradient as follows:

$$
q^{\prime \prime}=-\left.k_{n f} \frac{\left(T_{w}-T_{i}\right)}{w} \frac{\partial \theta}{\partial Y}\right|_{Y=1}
$$

Convective heat transfer coefficient, $h_{n f}$, is well known as:

$$
h_{n f}=\frac{q^{\prime \prime}}{\left(T_{w}-T_{i}\right)}
$$

Nusselt number is defined based on the width of channel and based fluid thermal conductivity and it can be written as follows:

$$
N u=\frac{h_{n f} w}{k_{f}}
$$

By combining Equations (13) and (14), it is possible to define Nusselt number as:

$$
N u=-\left.\frac{k_{n f}}{k_{f}} \frac{\partial \theta}{\partial Y}\right|_{Y=1}
$$

The average Nusselt number by considering two walls is defined as follows:

$$
N u_{\text {avg }}=\frac{2 n}{H} \int_{0}^{H} N u(Y) d Y
$$

where $n$ is taken as 1 for fully heated case (i.e. $N=1$ ) and 2 for partially heated cases (i.e. $N=4,8$, and 10) in this study. It should be mentioned that the average heat transfer coefficient is defined based on the total area of the heated sections in walls. For fully heated vertical plate, the total length of the heated portion in one wall is $\mathrm{H}$ while for partially heated case the total length of the heated portions in one wall is $\mathrm{H} / 2$.

\section{The numerical procedure and computational details}

The governing equations given by equations (1-4) are solved numerically in dimensionless form by the code

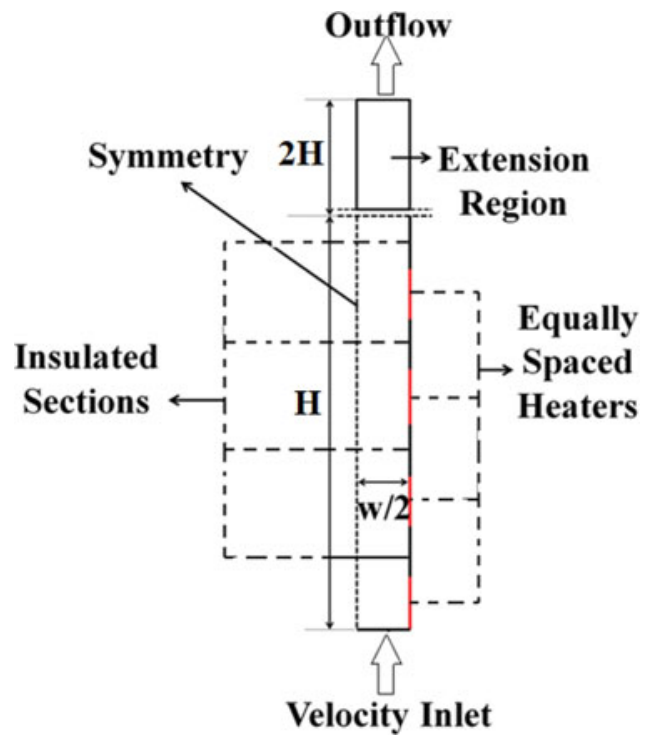

Figure 2. A view of computational domain with boundary condition.

ANSYS Fluent 15.0, which operates based on finite volume method. The coupling between velocity and pressure terms is handled by using Semi-Implicit Method for Pressure Linked Equations (SIMPLE) algorithm; while power law is considered for the discretization of convective terms in momentum and energy equations. The convergence criterion is set to $10^{-7}$ for continuity and the momentum equations, $10^{-12}$ for the energy equation. In addition to the convergence criteria, the velocity and temperature profiles at $Y=5, Y=10, Y=15$ are checked at different iteration steps and the solution is accepted as converged when there is no change between those profiles of different iteration levels. The walls of the channel are divided into uniformly heated, equal size of heated portions and insulated sections. An example of considered domain for 4 number of heater channel is shown in Figure 2. The half of the channel is considered as a computational domain due to the symmetry of the considered channel. A dummy extension section, height of $2 \mathrm{H}$, is considered above the main channel to overcome convergence difficulties due to the reverse flows at the outlet boundary. Our experience showed that the height of $2 \mathrm{H}$ for the length of dummy section is sufficient. Grid independency study is performed for two extreme cases as $\mathrm{Ri}=0.01, \operatorname{Re}=100, N=10, \phi=5 \%$ and $\mathrm{Ri}=10, \mathrm{Re}=$ $500, N=10$ and $\phi=5 \%$. The grid number is taken as 320 , $8000,18000,32000,50000$, and 72000 . As it can be seen in Figure 3, the mean Nusselt number does not change after $50000(100 \times 500)$ and the grid number of 72000 $(120 \times 600)$ is sufficient to obtain accurate results for this study. 


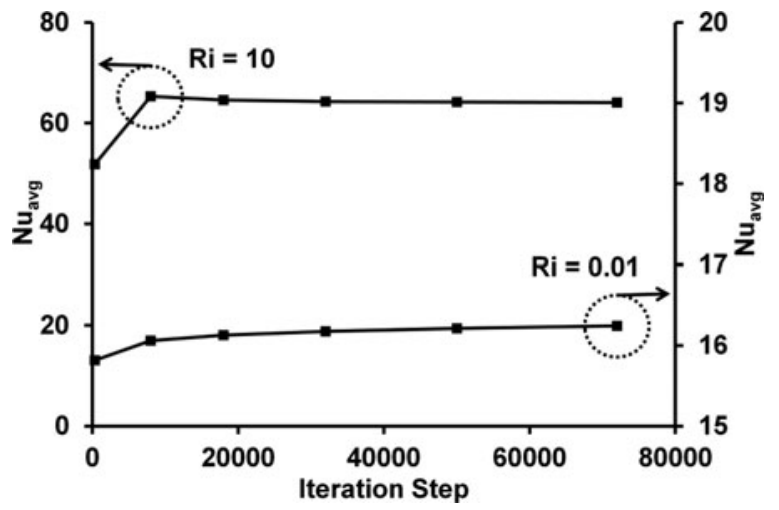

Figure 3. Grid independence study for two different channels as $\mathrm{Ri}=0.01, \operatorname{Re}=100$ and $\mathrm{Ri}=10, \operatorname{Re}=500$ when $\phi=5 \%$.

\section{Results and discussion}

\section{Validation of obtained results}

The computational method and the obtained results are validated with the study of Raisi et al. [36]. They considered magneto hydrodynamic mixed convection in a vertical channel filled with $\mathrm{Cu}$-water nanofluid. The entire surface of the channel is at constant and uniform temperature. The aspect ratio in their study is 40 . Grashof number is taken as $10^{5}$ and Pr number as 6.7. The comparison of the present study with Ref. [36] is done when magneto hydrodynamic effect is zero; in other words, Hartmann number (Ha) is taken as zero. It should be mentioned that Raisi et al. [36] included electromagnetic forces in their study and that is why they considered $\mathrm{Ha}$ in their study. $\mathrm{Ha}$ is defined as the ratio of electromagnetic force to the viscous force. As there is no electromagnetic force considered in our study, Ha is taken as zero. The validation is done for two cases as $\mathrm{Ri}=0.01$ and 10 for different volume fraction values when $\mathrm{Re}=100$. The comparison is done on the base of the mean Nusselt number and as it can be seen from Figure 4, a good agreement can be observed.

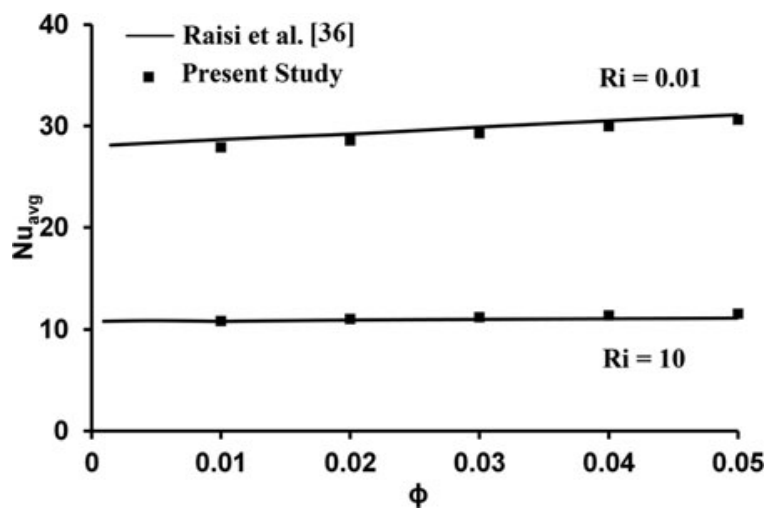

Figure 4. The comparison of the results of present study with Raisi et al. [36] when $\mathrm{Ri}=0.01$ and $10, \mathrm{Re}=100, \mathrm{Ha}=0$.

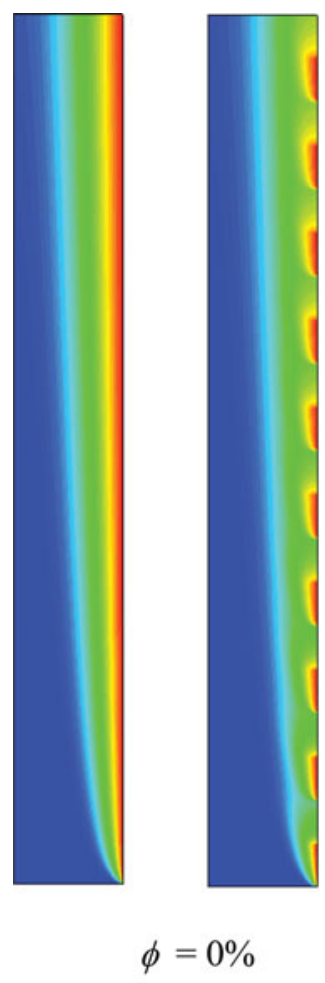

(a)

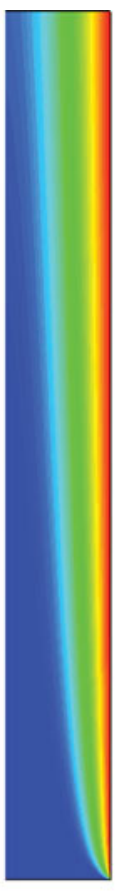

$\phi=5 \%$

(b)
Figure 5. Temperature distribution for $\mathrm{Ri}=0.01, \mathrm{Re}=100, N=1$, and $N=10$, (a) $\phi=0 \%$, (b) $\phi=5 \%$ (The scale of the $X$ direction is 5 times scale of the $Y$ direction).

The difference of the mean Nusselt number between Raisi et al. [36] and the present study is less than $2 \%$.

\section{Temperature and velocity fields}

Figure 5 shows temperature fields for a mixed convection in the channel for $\mathrm{Ri}=0.01$ and $\mathrm{Re}=100$, two different number of heated portions (i.e. $N=1$ and 10) and two different volume fraction values (i.e. $\phi=0 \%$ and 5\%). The width of the channel is extended 5 times for a better visualization. Figure 5(a) shows the dimensionless temperature contours for $\mathrm{Ri}=0.01, \mathrm{Re}=100$, and $\phi=0 \%$ when $N=1$ and 10 . As it can be seen from the temperature contours in Figure 5(a), the cold fluid moves a little bit longer distance in vertical direction when the number of the heater is 10 . By addition of nanoparticles into base fluid, as shown in Figure 5(b), the cold fluid flows relatively shorter distance in the $Y$ direction and the channel is heated faster compared to base fluid channel. Figure 6 shows the dimensionless temperature and velocity profiles at $Y=18.5$ for the cases of Figure 5. As can be seen in Figure 6(a), the dimensionless temperature gradient increases by increase of number of heated section for the same fluid since the cold air takes longer distance in the channel. By adding 


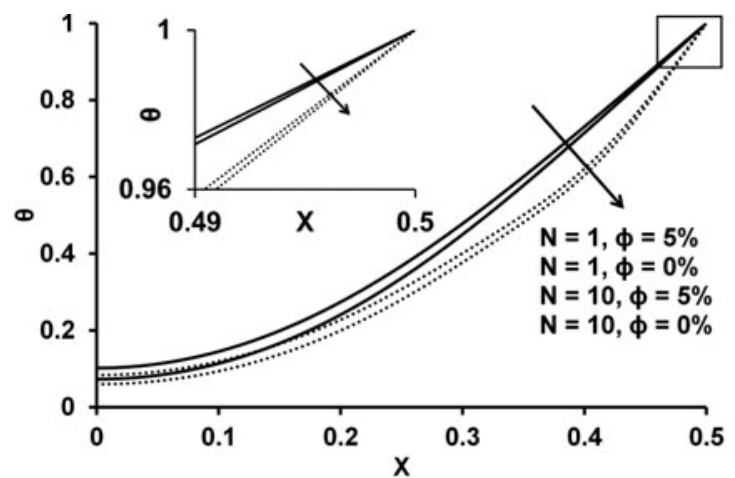

(a)

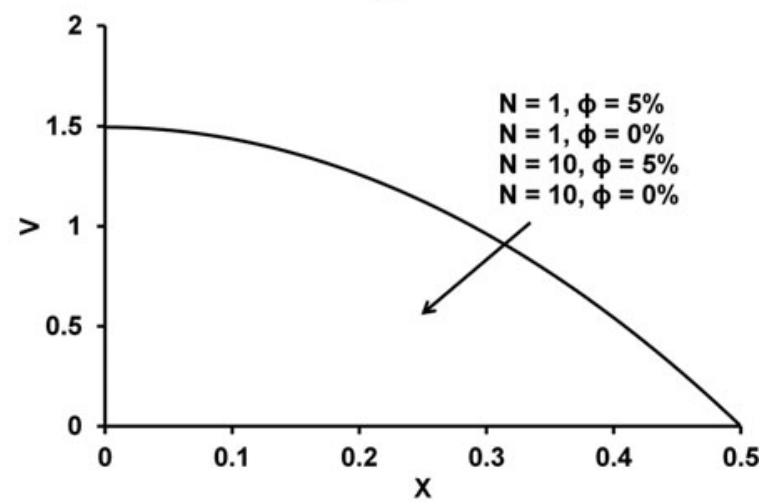

(b)

Figure 6. Dimensionless temperature and velocity profiles for $\mathrm{Ri}=$ $0.01, \operatorname{Re}=100, N=1$ and 10 at $Y=18.5$, (a) dimensionless temperature profiles, (b) dimensionless velocity profiles.

of nanoparticles in the channel, thermal conductivity both in transverse and longitudinal directions increases. Heat transfer becomes greater for the fluid involving nanoparticles compared to the channel filled with completely base fluid. That is why; dimensionless temperature profiles of the channel with nanoparticles become above the channel with clear fluid. Considering Figure 6(a), one may expect the decreasing of average Nusselt number by addition of the nanoparticles to the fluid since the temperature gradient at the surface decreases. However, due to the definition of Eq. (16), it is seen that the increase of thermal conductivity ratio, $\left(k_{n f} / k_{f}\right)$, not only may compensate the reduction of dimensionless temperature gradient at the surface but also increase the value of Nusselt number. Furthermore, dimensionless velocity profiles at $Y=18.5$ for $\mathrm{Ri}=0.01, \mathrm{Re}=100$ and two different number of heated portions (i.e. $N=1$ and 10) and two different volume fraction values (i.e. $\phi=0 \%$ and $5 \%$ ) can be seen from Figure $6(\mathrm{~b})$. The identical parabolic velocity profiles are observed for different number of heated portions and volume fraction values which means that forced convection is dominant inside the channel and the buoyancy effect of is negligible. As it can be seen from Figure 6(b), the number of the heated portions and volume fraction

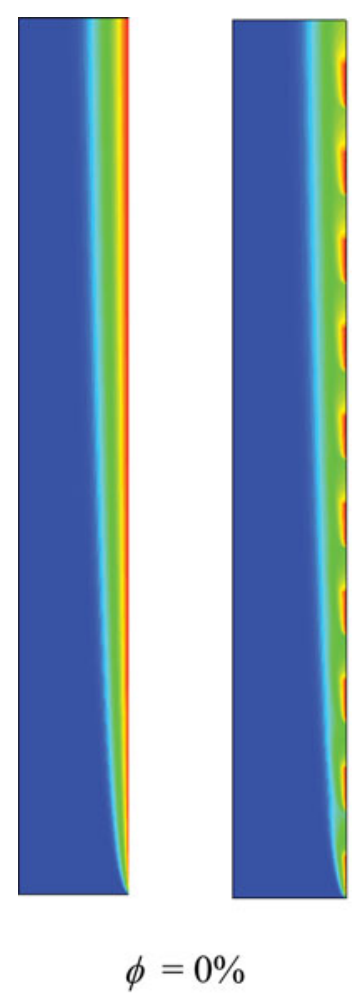

(a)

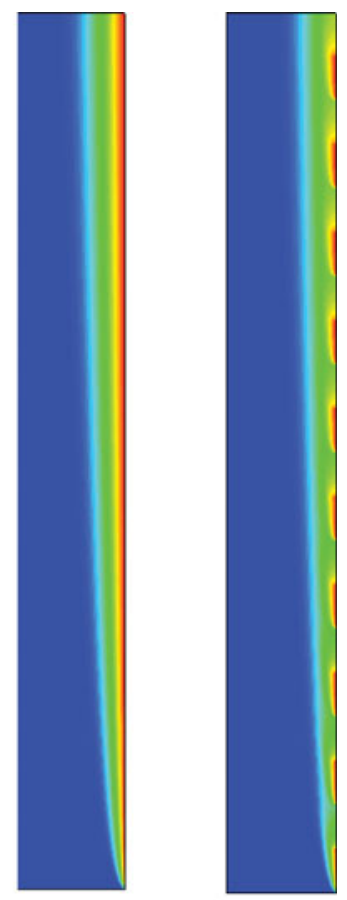

$\phi=5 \%$

(b)
Figure 7. Temperature distribution for $\mathrm{Ri}=0.01, \mathrm{Re}=500, N=1$, and $N=10$, (a) $\phi=0 \%$, (b) $\phi=5 \%$ (The scale of the $X$ direction is 5 times scale of the $Y$ direction).

value does not have considerable effect on velocity profile inside the channel.

Similarly, Figure 7 shows temperature fields for a mixed convection in the channel for $\mathrm{Ri}=0.01$ and $\mathrm{Re}=500$, two different number of heated portions as $N=1$ and 10 , and two different volume fraction values of $\phi=0 \%$ and $5 \%$. By increasing Re number from 100 to 500, the temperature in the middle region of channel decreases due to increase of forced convection effect. Hence for the same fluid, an increase in Nusselt number is expected when Re number increases from 100 to 500 . Figure 8 shows the dimensionless temperature profiles of Figure 7 at $Y=18.5$. It seems that by increasing Re number, dimensionless temperature profiles become closer to each other if Figure 8(a) and 6(a) are compared. Furthermore, there is no considerable difference in velocity profiles when Re is increased to 500 as can be seen from Figure 6(b) and 8(b).

Figure 9 shows temperature contours for $N=1$ and $10, \mathrm{Re}=100$ and $\mathrm{Ri}$ number of 10 and for two volume fraction values as $\phi=0 \%$ and $5 \%$. By increasing Ri number, buoyancy effects inside the channel increases and the differences between temperature profiles inside the channels become more visible. The velocity of the fluid near 


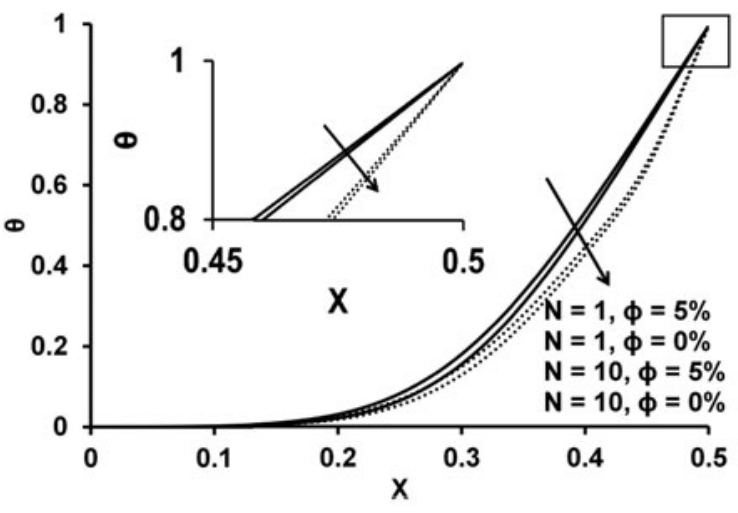

(a)

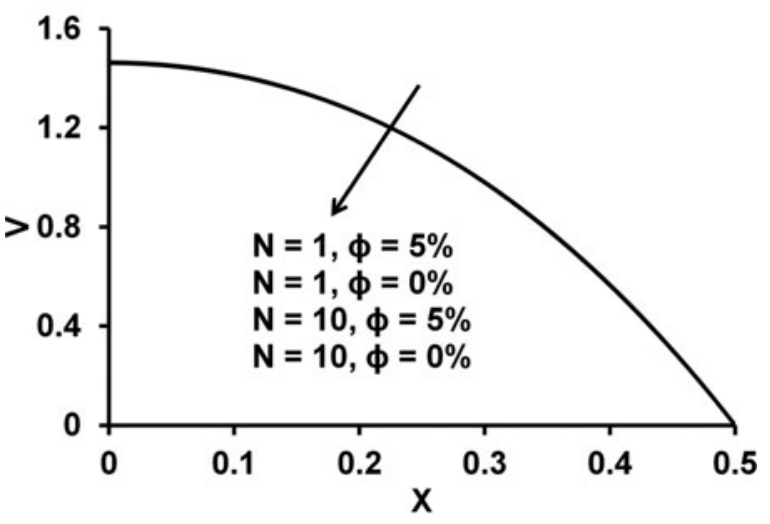

(b)

Figure 8. Dimensionless temperature and velocity profiles for $\mathrm{Ri}=0.01, \operatorname{Re}=500, N=1$, and $N=10$ at $Y=18.5$, (a) dimensionless temperature profiles, (b) dimensionless velocity profiles.

hot wall increases as its density increases due to temperature difference. Therefore, flow reversals are seen inside the channel due to fixed flow rate. That is why, the dimensionless temperature contours change direction to downward at the middle region of the channel. Similarly, the dimensionless temperature profiles of Figure 9 at $Y=18.5$ are plotted and shown in Figure 10(a). As can be seen, by increasing of Ri number, the differences between the temperature profiles of different cases increases. When the number of heated section increases, the gradient of the temperature at the wall surface also increases since discontinuous heating exits. Furthermore, by adding of nanoparticles, the fluid is heated faster in the inlet of the channel and dimensionless temperature of nanofluid becomes above of the clear fluid temperature profile. Dimensionless velocity profiles of Figure 10(a) are given in Figure 10(b). As it can be seen on Figure 10(b), the increase of Ri number causes flow reversals inside the channel due to fixed flow rate. By addition of nanoparticles into base fluid, the velocity of the flow with nanofluid near the hot wall decreases compared to the flow with the base fluid since the temperature gradient decreases near the hot wall.
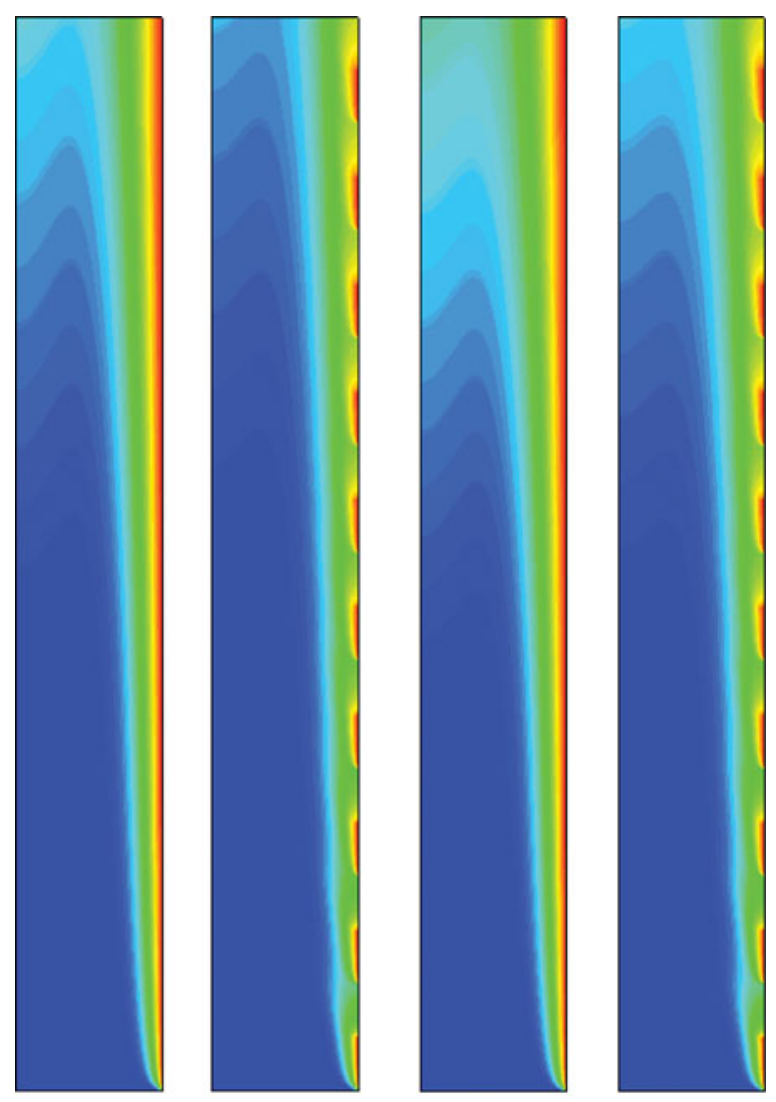

$\phi=0 \%$

(a) $\phi=5 \%$

(b)
Figure 9. Temperature distribution for $\mathrm{Ri}=10, \mathrm{Re}=100, N=1$, and $N=10$, (a) $\phi=0 \%$, (b) $\phi=5 \%$ (The scale of the $X$ direction is 5 times scale of the $Y$ direction).

Figure 11 shows the temperature distribution for $N=1$ and $10, \mathrm{Ri}=10$, and $\mathrm{Re}=500$ for two volume fraction value of $\phi=0 \%$ and $\phi=5 \%$. Similar to Figure 7, the increase in Re number causes the increase in velocity therefore, fluid flows faster inside the channel and less interaction between hot and cold fluid occurs. Therefore, temperature at the middle of the channel decreases and large region in the middle of the channel is at inlet temperature. Figure 12 shows dimensionless temperature and velocity profiles at $Y=18.5$ for the cases considered in Figure 11. As can be seen in Figure 12(a), temperature gradient at the wall is highly increased compared to the Figure 10(a), however the dimensionless temperature profiles of different cases at $Y=18.5$ become closer to each other. As shown in Figure 12(b), due to the increase of dimensionless temperature gradient near the hot wall and the consequently velocity near the hot wall increases. Due to the fixed flow rate and the increase of temperature gradient near the hot wall, the velocity in 


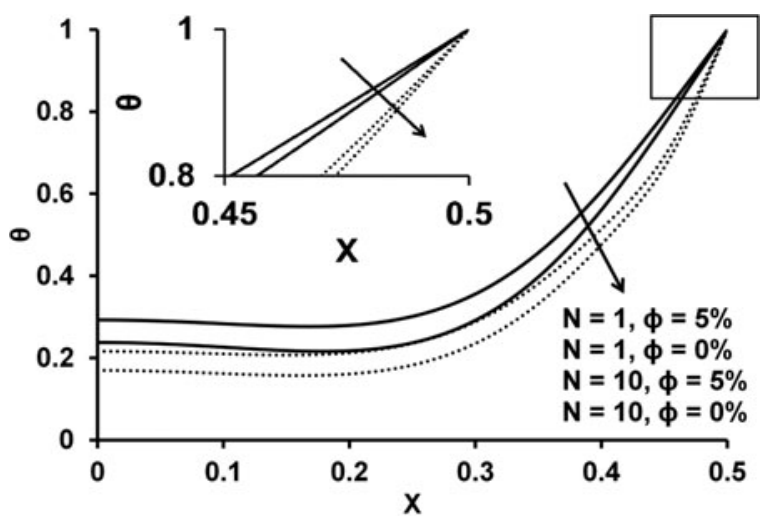

(a)

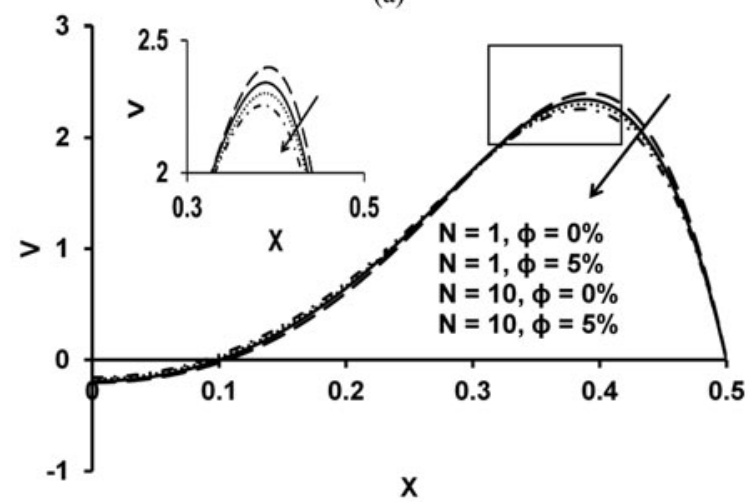

(b)

Figure 10. Dimensionless temperature and velocity profiles for $\mathrm{Ri}=10, \operatorname{Re}=100, N=1$, and $N=10$ at $Y=18.5$, (a) dimensionless temperature profiles, (b) dimensionless velocity profiles.

the middle of the channel is very small but no reverse flow in the middle of the channel occurs. It is possible to conclude that by adding nanoparticles into the base fluid, the velocity near the hot wall only in a narrow region is increased and therefore, a chance of occurrence of flow reversal in the middle region decreases when $\operatorname{Re}=500$.

\section{Average Nusselt number}

The variation of average Nusselt number with number of heated section when $\mathrm{Ri}=0.01$ and for two values of Re number as 100 and 500, and for two different volume fraction value as $\phi=0 \%$ and 5\% is shown in Figure 13(a). As it can be seen from figure, the average Nusselt number increases with increase number of heated section. The smallest average Nusselt is observed for the plate fully heated. There is no doubt that by increasing of number of heated area average $\mathrm{Nu}$ number increases. For instance, the increase of number heated portion for a channel with $\mathrm{Ri}=0.01, \operatorname{Re}=100$ and $\phi=5 \%$ from $N=1$ to 4 increases the average Nusselt number by $54 \%$. It is observed that if the number of heated section increases, the average Nusselt number also increases, however the rate of increase
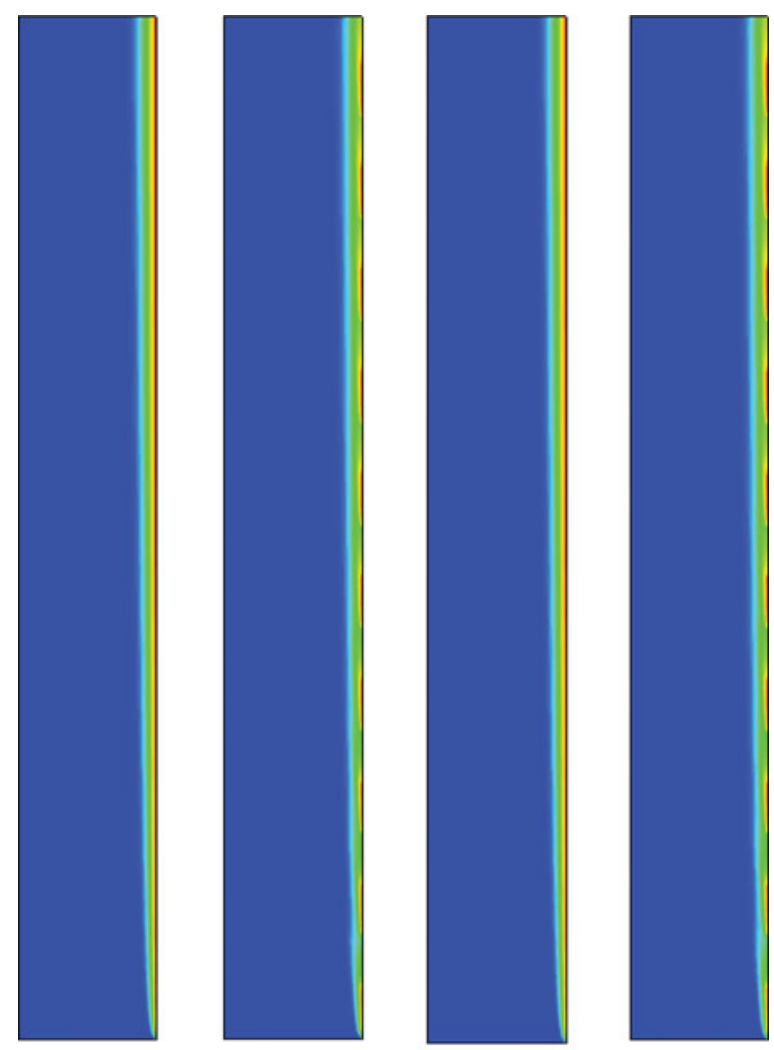

$$
\phi=0 \%
$$

$\phi=5 \%$

(a)

Figure 11. Temperature distribution for $\mathrm{Ri}=10, \mathrm{Re}=500, N=1$, and $N=10$, (a) $\phi=0 \%$, (b) $\phi=5 \%$ (The scale of the $X$ direction is 5 times scale of the $Y$ direction).

is not too much. For instance, the increase in number of heated portion from 4 to 10 increases $N u_{\text {avg }}$ by $7 \%$. The reason for the increase may be the destruction of thermal boundary layer which prevents the growing of thermal boundary layer thickness. The average Nusselt number also increases by increasing Re number due to increase of forced convection effect and increase of temperature gradient at the wall. For instance, for a channel with $\mathrm{Ri}=0.01, N=10$, and $\phi=5 \%$, the increase of Re number from 100 to 500 increases the average Nusselt number by $83 \%$. Finally, the enhancement of heat transfer by adding nanoparticles into the fluid can also be observed from Figure 13(b). The addition of nanoparticles by $5 \%$ in a channel with $\mathrm{Ri}=0.01, \mathrm{Re}=100$ and $N=10$, increases $N u_{\text {avg }}$ by $9.7 \%$. When Ri number is increased from 0.01 to 10 , the effect of number of heated portion and nanoparticle concentration becomes more visible. The $N u_{\text {avg }}$ is increased by $47 \%$ if the number heated portion for a channel with $\mathrm{Ri}=10, \mathrm{Re}=500$ and $\phi=$ $5 \%$ is increased from $N=1$ to 4 and further increase in the number of heated portion from 4 to 10 increases the 


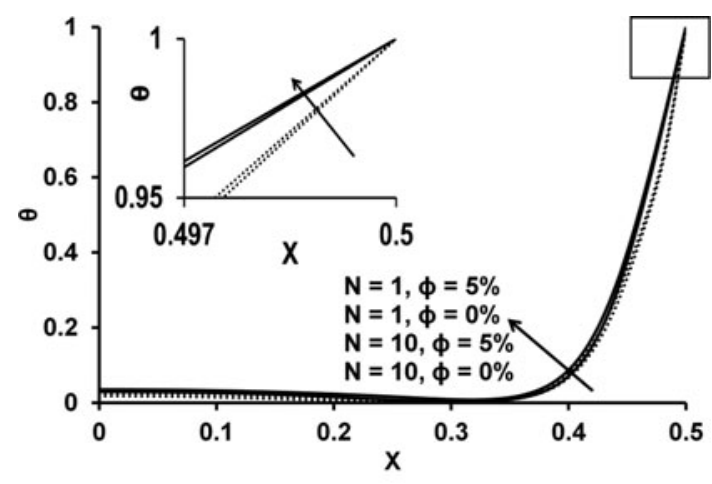

(a)

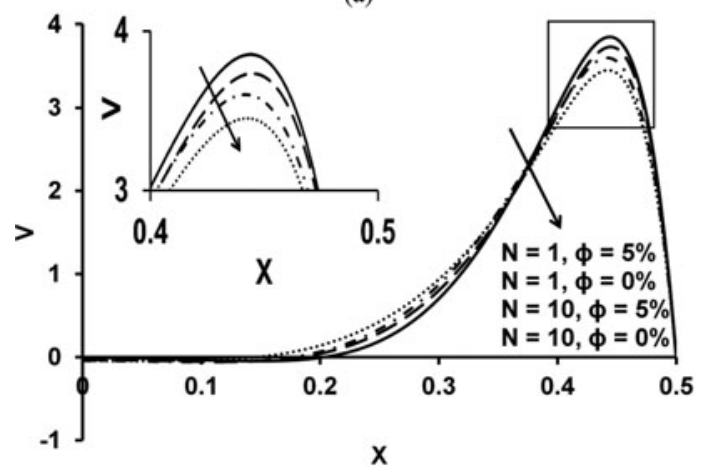

(b)

Figure 12. Dimensionless temperature and velocity profiles for $\mathrm{Ri}=10, \operatorname{Re}=500, N=1$, and $N=10$ at $Y=18.5$, (a) dimensionless temperature profiles, (b) Dimensionless velocity profiles.

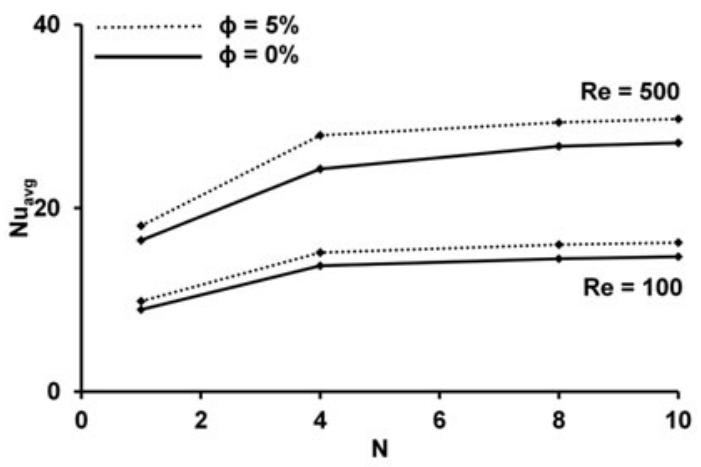

(a)

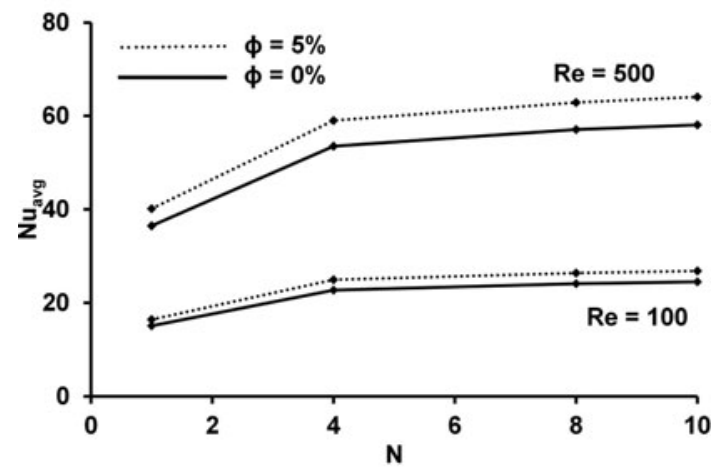

(b)

Figure 13. Variation of average Nusselt number with number of heated section, $\operatorname{Re}$ and $\phi$, (a) $\mathrm{Ri}=0.01$, (b) $\mathrm{Ri}=10$. average Nusselt number by $9 \%$. Similarly for a channel with $\mathrm{Ri}=10, \mathrm{Re}=500$, and $N=10, N u_{\text {avg }}$ is increased by $10.4 \%$ if the nanoparticle concentration is increased by $5 \%$. By increase of Richardson number, the coupling of temperature and velocity fields becomes stronger. A small change in temperature field changes the velocity field and it will influence the temperature profiles. That is why, the increase of number of heated section or adding nanoparticles considerably affects $N u_{\text {avg }}$

\section{Conclusions}

In this study, mixed convection heat and fluid flow inside a partially heated vertical channel filled with $\mathrm{Al}_{2} \mathrm{O}_{3}$ nanoparticles is analyzed. Four different heating cases with number of heated section of $1,4,8$, and 10 are considered in this study. The governing equations are solved numerically in dimensionless form. Based on the obtained results, following remarks can be concluded from this study:

- The buoyancy effect particularly at the region close to the heated wall is added to the effect of pressure gradient by increase of Ri number. This causes reversal flows in the channel and consequently the increase of Nusselt number. By increasing Ri number from 0.01 to 10 for the channel with $N=1$ and $\phi=5 \%$, the mean Nusselt number increases $67 \%$ for $\operatorname{Re}=100$ and $122 \%$ for $\operatorname{Re}=500$.

- The mean Nusselt number increases with the number of heaters on the wall. However, the rate of increase depends on Re number. The rate of increase is higher for high values of Re number (i.e. $\operatorname{Re}=500$ ).

- The use of nanoparticle in fluid increases heat transfer rate in the channels. It seems that the rate of increase depends on both Reynolds and Richardson numbers. High values of Reynolds and Richardson number yield higher heat transfer enhancement. For the channel with $\mathrm{Ri}=10, N=10$, and $\mathrm{Re}=500$, the mean Nusselt number increases $10.4 \%$ by adding $5 \%$ nanoparticle into the base fluid.

For future studies, the optimization of channel geometry based on the governing dimensionless parameters and length and number of heated sections for maximum mixed convection heat transfer from the channel with considering of the second law analysis can be done. Similar geometry under constant heat flux boundary conditions can also be analyzed. It is also possible to obtain a correlation for determination of Nusselt number in terms of governing equations which will be helpful for the researchers who work in thermal engineering area. 


\section{Nomenclature}

$c_{\mathrm{p}} \quad$ Specific heat at constant temperature, $\mathrm{J} / \mathrm{kgK}$

$g$ Gravitational acceleration, $\mathrm{m} / \mathrm{s}^{2}$

Gr Grashof number, defined in Eq. (5)

$h$ Convective heat transfer coefficient, $\mathrm{W} / \mathrm{m}^{2} \mathrm{~K}$

$H$ Height, m

$\mathrm{Ha}$ Hartmann number

$k$ Thermal conductivity, $\mathrm{W} / \mathrm{mK}$

$n$ A constant

$N$ Number of the heaters on the wall

$\mathrm{Nu}$ Nusselt number

$p$ Pressure, $\mathrm{Pa}$

$P \quad$ Dimensionless pressure, defined in Eq. (5)

Pr Prandtl number

$q^{\prime \prime} \quad$ Wall heat flux, $\mathrm{W} / \mathrm{m}^{2}$

Re Reynolds number, defined in Eq. (5)

$R i$ Richardson number, defined in Eq. (5)

$T$ Temperature, $\mathrm{K}$

$u \quad$ Velocity in the $x$-direction, $\mathrm{m} / \mathrm{s}$

$\mathrm{v}$ Velocity in the $y$-direction, $\mathrm{m} / \mathrm{s}$

$U$ Dimensionless velocity in the $x$-direction

$V \quad$ Dimensionless velocity in the $y$-direction

$w \quad$ Width, $\mathrm{m}$

$x, y \quad$ Dimensional axial and transverse directions, $\mathrm{m}$

$X, Y \quad$ Dimensionless axial and transverse directions

\section{Greek symbols}

$\alpha \quad$ Thermal diffusivity, $\mathrm{m}^{2} / \mathrm{s}$

$\beta \quad$ Thermal expansion coefficient, $1 / \mathrm{K}$

$\theta$ Dimensionless temperature, defined in Eq. (5)

$\mu$ Dynamic viscosity, Pa.s

$v$ Kinematic viscosity, $\mathrm{m}^{2} / \mathrm{s}$

$\rho \quad$ Density, $\mathrm{kg} / \mathrm{m}^{3}$

$\phi \quad$ Solid volume fraction

\section{Subscripts}

$\begin{aligned} \text { avg } & \text { Average } \\ f & \text { Fluid } \\ i & \text { Inlet } \\ n f & \text { Nanofluid } \\ s & \text { Solid } \\ w & \text { Wall }\end{aligned}$

\section{Notes on contributors}

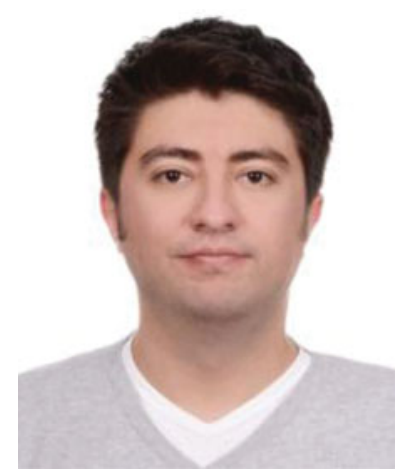

Hasan Celik is currently Research Assistant and Ph.D. student at Izmir Institute of Technology. He received his B.S. degree in Mechanical Engineering in 2010 from Ataturk University and his M.Sc. degree in 2012 from Izmir Institute of Technology. His research interests include heat and fluid flow in porous media, convective heat transfer, fluid mechanics and nanofluids. He is a member of ASME and SigmaXi.

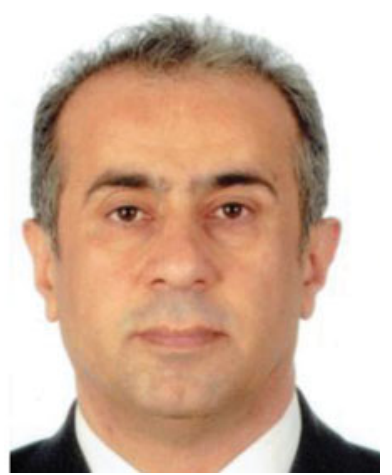

Moghtada Mobedi received his Ph.D. degree in Mechanical Engineering in 1994 from Middle East Technical University in Turkey. He worked in Orumieh University in Iran, research and development department of a HVAC company and Izmir Institute of Technology in Turkey for many years. Currently, he works in Faculty of Engineering of Shizuoka University as an associate professor. His research areas include heat, mass and fluid flow in porous media, adsorption heat pump and adsorption thermal storage, computational heat and mass transfer, natural and mixed convection heat transfer. He has published more than 100 journal and international conference papers.

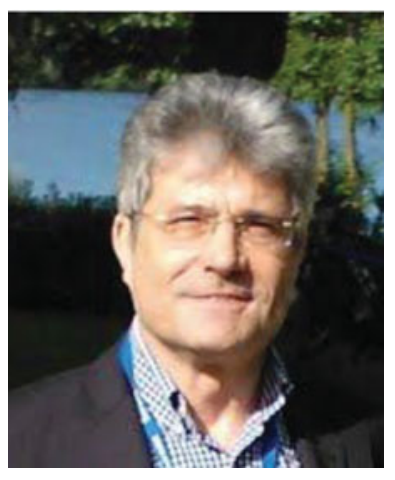

Oronzio Manca is professor of Mechanical Engineering at Seconda Università degli Studi di Napoli. The main scientific activities are on active solar systems; passive solar systems; refrigerant fluids; natural and mixed convection in open ended cavity with and without porous media; conduction in solids irradiated by moving heat sources; combined radiative and conductive fields in multilayer thin films; analytical and numerical solutions in material processing; thermal control of electronic equipment and solar systems, heat transfer augmentation by nanofluids. He is member of the American Society of Mechanical Engineering, Unione Italiana di Termofluidodinamica UIT. He is author or coauthor of 115 peer reviewed journal papers and 7 book chapters. $\mathrm{He}$ is coauthor of the book Applied Diffusion Processes from Engineering to Finance, Wiley-ISTE (2013) and co-editor of the book Heat Transfer Enhancement with Nanofluids, CRC, Taylor and Francis Group (2015). Associate Editor for the ASME Journal of Heat Transfer and Journal of Porous Media

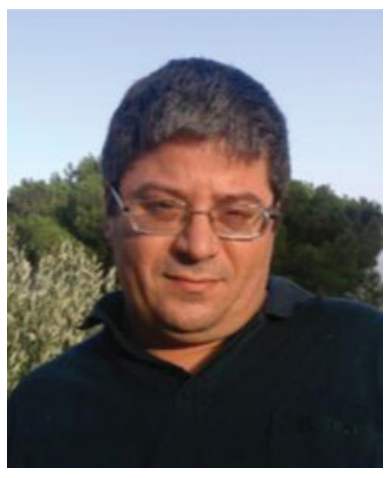

Bernardo Buonomo is currently a Technical Researcher at Seconda Universita degli Studi di Napoli. He received his Ph.D. degree in Aerospace Science and Technology in 2003 from Seconda Università degli Studi di Napoli. His research interests include analysis of active and passive solar systems, thermodynamics analysis of natural convection in open-ended cavities, analysis of heat transfer in porous media, microchannels, and nanofluids. 


\section{References}

[1] Choi, S. U. S., Zhang, Z. G., Yu, W., and Lockwood, F. E., Anomalously Thermal Conductivity Enhancement in Nanotube Suspensions, Applied Physics Letters, vol. 79, pp. 2252-2254, 2001.

[2] Bianco, V., Manca, O., Nardini, S., and Vafai, K., Heat Transfer Enhancement with Nanofluids, Publisher CRC, Taylor and Francis Group, Boca Raton, FL, USA, 2015.

[3] Mahian, O., Kianifar, A., Kalogirou, S. A., Pop, I., and Wongwises, S., A Review of the Applications of Nanofluids in Solar Energy, International Journal of Heat and Mass Transfer, vol. 57, no. 2, pp. 582-594, 2013.

[4] Mahian, O., Kianifar, A., Kleinstreuer, C., Al-Nimr, M. A., Pop, I, Sahin, A. Z., and Wongwises, S., A Review of Entropy Generation in Nanofluid Flow, International Journal of Heat and Mass Transfer, vol. 65, pp. 514-532, 2013.

[5] Wen, D., Lin, G., Vafaei, S., and Zhang, K., Review of Nanofluids for Heat Transfer Applications, Particuology, vol. 7, no. 2, pp. 141-150, 2009.

[6] Liu, Z. H., and Li, Y. Y., A New Frontier on Nanofluid Research - Application of Nanofluids in Heat Pipes, International Journal of Heat and Mass Transfer, vol. 55, pp. 6786-6797, 2012.

[7] Saidur, R., Leong, K. Y., and Mohammad, H. A., A Review on Applications and Challenges of Nanofluids, Renewable and Sustainable Energy Reviews, vol. 15, pp. 1646-1668, 2011.

[8] Huminic, G., and Huminic, A., Application of Nanofluids in Heat Exchangers: A Review, Renewable and Sustainable Energy Reviews, vol. 16, pp. 5625-5638, 2012.

[9] Das, S. K., Choi, S. U. S., and Patel, H. E., Heat Transfer in Nanofluids - A Review, Heat Transfer Engineering, vol. 27, no. 10, pp. 3-19, 2006.

[10] Yu, W., France, D. M., Routbort, J. L., and Choi, S. U. S., Review and Comparison of Nanofluid Thermal Conductivity and Heat Transfer Enhancements, Heat Transfer Engineering, vol. 29, no. 5, pp. 432-460, 2008.

[11] Wong, K. V., and De Leon, O., Applications of Nanofluids: Current and Feature, Advances in Mechanical Engineering, vol. 2, pp. 519659-1-519659-11, 2010.

[12] Rashidi, I., Mahian, O., Lorenzini, G., Biserni, C., and Wongwises, S., Natural Convection of Al2O3/Water Nanofluid in a Square Cavity: Effects of Heterogeneous Heating, International Journal of Heat and Mass Transfer, vol. 74, pp. 391-402, 2014.

[13] Poskas, P., and Poskas, R., Mixed Convection In Channel Flows, Heat Transfer Research, vol. 40, no. 1, pp. 31-56, 2009.

[14] Oztop, H. F., and Al-Salem, K., A Review on Entropy Generation in Natural and Mixed Convection Heat Transfer for Energy Systems, Renewable and Sustainable Energy Reviews, vol. 16, no. 1, pp. 911-920, 2012.

[15] Hughes, B. R., Calautit, J. K., and Ghani, S. A., The Development of Commercial Wind Towers for Natural Ventilation: A Review, Applied Energy, vol. 92, pp. 606-627, 2012.

[16] Nicolas, X., Zoueidi, N., and Xin, S., Influence of a White Noise at Channel Inlet on the Parallel and Wavy Convective Instabilities of Poiseuille-Rayleigh-Bénard Flows, Physics of Fluids, vol. 24, no. 8, pp. 084101-1-084101-28, 2012.
[17] Wei, T., A, Review of Sensitivity Analysis Methods in Building Energy Analysis, Renewable and Sustainable Energy Reviews, vol. 20, pp. 411-419, 2013.

[18] Dawood, H. K., Mohammed, H. A., Che Sidik, N.A., Munisamy, K. M., and Wahid, M. A., Forced, Natural and Mixed-Convection Heat Transfer and Fluid Flow in Annulus: A Review, International Communications in Heat and Mass Transfer, vol. 62, pp. 45-57, 2015.

[19] Obyn, S., and Van Moeseke, G., Variability and Impact of Internal Surfaces Convective Heat Transfer Coefficients in the Thermal Evaluation of Office Buildings, Applied Thermal Engineering, vol. 87, pp. 258-272, 2015.

[20] Daungthongsuk, W., and Wongwises, S., A Critical Review of Convective Heat Transfer Nanofluids, Renewable and Sustainable Energy Reviews, vol. 11, pp. 797-817, 2007.

[21] Wang, X. Q., and Mujumdar, A. S., A Review on Nanofluids. Part I: Theoretical and Numerical Investigations, Brazilian Journal of Chemical Engineering, vol. 25, pp. 613-630, 2008.

[22] Kakac, S., and Pramuanjaroenkij, A., Review of Convective Heat Transfer Enhancement with Nanofluids, International Journal of Heat and Mass Transfer, vol. 52, pp. 3187-3196, 2009.

[23] Memari, M., Golmakani, A., and Dehkordi, A. M., MixedConvection Flow of Nanofluids and Regular Fluids in Vertical Porous Media with Viscous Heating, Industrial and Engineering Chemistry Research, vol. 50, no. 15, pp. 9403 9414, 2011.

[24] Van Gorder, R. A., Prasad, K. V., and Vajravelu, K., Convective Heat Transfer in the Vertical Channel Flow of a Clear Fluid Adjacent to a Nanofluid Layer: A Two-Fluid Model, Heat and Mass Transfer, vol. 48, no. 7, pp. 12471255, 2012.

[25] Amrei, S. M. H., and Dehkordi, A. M., Modeling and CFD Simulation of a Mixed Convection Flow of Regular Fluids and Nanofluids in Vertical Porous and Regular Channels, Heat Transfer-Asian Research, vol. 43, no. 3, pp. 243-269, 2014.

[26] Grosan, T., and Pop, I., Fully Developed Mixed Convection in A Vertical Channel Filled by a Nanofluid, Journal of Heat Transfer, vol. 134, no. 8, pp. 082501-1-082501-5, 2012.

[27] Hajipour, M., and Dehkordi, A. M., Analysis of Nanofluid Heat Transfer in Parallel-Plate Vertical Channels Partially Filled with Porous Medium, International Journal of Thermal Sciences, vol. 55, pp. 103-113, 2012.

[28] Xu, H., Fan, T., and Pop, I., Analysis of Mixed Convection Flow of a Nanofluid in a Vertical Channel with the Buongiorno Mathematical Model, International Communications in Heat and Mass Transfer, vol. 44, pp. 15-22, 2013.

[29] Farooq, U., and Zhi-Liang, L., Nonlinear Heat Transfer in a Two-Layer Flow with Nanofluids by OHAM, Journal of Heat Transfer, vol. 136, no. 2, pp. 021702-1-021702-8, 2014.

[30] Malvandi, A., and Ganji, D. D., Mixed Convective Heat Transfer of Water/Alumina Nanofluid Inside a Vertical Microchannel, Powder Technology, vol. 263, pp. 37-44, 2014.

[31] Hajipour, M., Dehkordi, A. M., and Jamshidi, S., Numerical Investigation of Nanofluid Mixed-Convection Flow in 
the Entrance Region of a Vertical Channel Partially Filled with Porous Medium, Heat Transfer - Asian Research, vol. 43, no. 7, pp. 607-627, 2014.

[32] Fakour, M., Vahabzadeh, A., and Ganji, D. D., Scrutiny of Mixed Convection Flow of a Nanofluid in a Vertical Channel, Case Studies in Thermal Engineering, vol. 4, pp. 15-23, 2014.

[33] Chen, C. K., Chen, B. S., and Liu, C. C., Heat Transfer and Entropy Generation in Fully-Developed Mixed Convection Nanofluid Flow in Vertical Channel, International Journal of Heat and Mass Transfer, vol. 79, pp. 750-758, 2014.

[34] Hajipour, M., and Dehkordi, A. M., MixedConvection Flow of $\mathrm{Al}_{2} \mathrm{O}_{3}-\mathrm{H}_{2} \mathrm{O}$ Nanofluid in a
Channel Partially Filled with Porous Metal Foam: Experimental and Numerical Study, Experimental Thermal and Fluid Science, vol. 53, pp. 49-56, 2014.

[35] Moghari, M. R., Talebi, F., Rafee, R., and Shariat, M., Numerical Study of Pressure Drop and Thermal Characteristics of $\mathrm{Al}_{2} \mathrm{O}_{3}$-Water Nanofluid Flow in Horizontal Annuli, Heat Transfer Engineering, vol. 36 no. 2, pp. 166177, 2015.

[36] Raisi, A., Aminossadati, S. M., and Ghasemi, B., Magnetohydrodynamic Mixed Convection of a $\mathrm{Cu}$ - Water Nanofluid in a Vertical Channel, Journal of Heat Transfer, vol. 135, pp. 74501-1-74501-4, 2013. 